\title{
Vulture SPECIALIST GROUP IUCN SPECIES SURVIVAL COMMISSION
}

\section{Vulture updates - March 2018 - Around the World of Vultures \& VSG activities}

This biannual newsletter of the IUCN Vulture Specialist Group features updates on the CMS Multi-Species Action plan (MsAP), but again more alarming poisoning incidents from around the world underline the priority of this threat within the MsAP and globally; this time, these headlines are also from South America for Andean condors as well as from Africa and elsewhere. More positive are updates including new tracking projects of Egyptian vultures in Arabia, Eurasian Griffons in Europe, and Nepalese wild and for the first time released white-rumped vultures in South Asia. Read on for more updates from around the globe...

Perhaps the most significant news is that the CMS Vulture MsAP (Old World vultures action plan) was endorsed and adopted at the CMS COP12 in Manila, Philippines in October 2017. The action plan document (available here) contains a lot of updated information, but most significantly, provides an agreed framework for priority actions to conserve the 15 Old World vulture species in Africa-Eurasia. We take this opportunity to thank all VSG members and contributors who participated in the drafting of this important document. However, the adoption of the plan is just the beginning, and the most critical step, its implementation, is the new challenge that requires more capacity and substantial funding. The VSG will continue working with partners, members, and the range governments to secure the resources and support crucially needed.

A wildlife poisoning discussion forum has been set up with over 150 experts participating worldwide. Contact ngaio@wd4c.org directly if you're interested in participating.

\section{Africa Round-up}

First, three recent poison-bait incidents, all in Feb 2018: 40 vultures died in a $15 \mathrm{~km}$ radius over a two-week period $30 \mathrm{~km} \mathrm{NE}$ of Masai Mara's Sekenani Gate, Kenya - the source so far unclear but appears to be outside the PA. Other retaliatory poisonings involved $\underline{6 \text { lions }}$ and 72 vultures in Ruaha, Tanzania and $\underline{103}$ birds killed in Gorongosa National Park, Mozambique which had fed on an elephant carcass, and a further 50 birds were also poisoned in the area.

Vulture population monitoring in southern Tanzania completed five years of surveys in 2017 by WCS \& N Carolina Zoo. Monitoring of 8 satellite tagged vultures ( 7 White-backed and 1 White-headed) since Oct 2016 suffered no mortalities in 2017, although there was a report of vulture parts at a poaching camp in Katavi NP in Nov 2017. The team also organised Tanzania's first IVAD event in Sept 2017 near Ruaha NP with several government officials and over 750 community members present. On 8 Nov 2017, VulPro released 35 vultures at the Nooitgdacht Cape Vulture breeding colony in the Magaliesberg, South Africa. 20 of these were captive-bred Cape Vultures, the rest were rehabilitated vultures of 3 different species. Each was fitted with patagial (wing) tags and a tracking device. All except one Lappet-faced Vulture had been acclimatised for 6 months in a purpose-built release enclosure on a mountaintop cliff edge. This is the first release of its kind in Africa, allowing direct comparisons of subsequent survival between captive-bred and rehabilitated vultures for future reference with potential 
implications elsewhere for releases of these species. Kenya Wildlife Service (KWS) in collaboration with Nature Kenya have developed a Response Protocol to Illegal Wildlife Poisoning as a means to deliver a rapid and effective response to wildlife poisoning incidents in Kenya. Input to the protocol was provided by various experts and stakeholders including The Peregrine Fund and BirdLife International. Training of KWS vets, rangers and conservation groups on the implementation of the protocol will be conducted in 2018. A similar protocol has been developed in Botswana by BirdLife Botswana in collaboration with the Dept. Wildlife \& National Parks (DWNP). The Peregrine Fund's Stop Poisoning Now campaign continues to raise awareness about wildlife poisoning and vultures at the grass-roots level in northern Kenya and has trained 233 participants from 35 local and national organisations in how to respond to a poisoning incident. One poisoning targeting lions has already been prevented and first aid advice given to a young girl who swallowed poison. Currently 18 vultures (of 4 species) are being tracked. One White-backed Vulture tagged in the Masai Mara was poisoned within two months. Conservation Wildlife Fund vet Richard Hoare was supported by BirdLife Zimbabwe (BLZ) to develop information from Dr Masterson's Practical Case Management into a brief focusing on cyanide poisoning. BLZ in collaboration with Zimbabwe Parks and Wildlife Management Authority shared the brief and provided basic training to 59 rangers from Hwange National Park, Kazuma NP and Zambezi NP in July 2017. Also in southern Africa, a recent poisoning incident which resulted in the loss of 3 Lappet-faced Vultures in the vicinity of the Namib-Naukluft National Park (Namibia) resulted in a poisoning intervention training workshop being presented to 27 delegates from a range of organisations and including farmers from the area at the Sossusvlei Lodge in Nov
2017. Further training workshops are planned for Namibia, Botswana and Zambia in 2018.

\section{West Africa}

Mohamed Henriques and colleagues published the first detailed information on vulture populations in Guinea-Bissau. In North Africa: A two-day vulture monitoring and tagging training was convened in Rabat, Morocco in Apr 2017 by IUCN Med, NGOs and Moroccan wildlife authorities. A new breeding site of EV was discovered in the Middle Atlas in 2017 by Nature Solution and will be monitored in 2018. A new Bearded vulture territory was reported in Alto NP, Eastern Atlas, and a Spanish-ringed Eurasian Griffon 'UFC' has been seen at Pointe de la Sarga, Western Sahara where it remained to at least Feb 2018. Meanwhile Rüppell's Vulture sightings have become more regular in Morocco in recent years, apparently following the same movement patterns as Eurasian Griffons through Gibraltar Straits and Western Sahara. One was near Dakhla Jun 2017.

A reminder to submit any poisoning incident details (of any species) to africanwildlifepoisoning.org

\section{Asia Round-up}

The first releases for any of the Critically Endangered species went ahead successfully in the terai of Nepal in Nov 2017 with six captivereared White-rumped Vultures (WRV) tagged and released. Meanwhile 6 more wild WRV were tagged by the BCN/RSPB team and movements of these and all 11 tagged since Apr 2017 continue to highlight new feeding sites in Nepal and India. One adult wild bird surprisingly travelled 900km west to Himachal Pradesh and back again, but the others mainly remained within the $100 \mathrm{~km}$ Vulture Safe Zone (VSZ) radius. Meanwhile the released birds 
have so far not moved beyond a $2 \mathrm{~km}$ radius. Further updates will be posted on SAVE news. Releases in India are now set for later in 2018 once surveys have been completed to confirm low diclofenac levels within the $100 \mathrm{~km}$ release zone, and with tagging permissions in place. There was major relief in Nov 2017 when Madras High Court upheld the Indian Government's 2015 ban of multi-dose vials of human diclofenac. SAVE acknowledged partners Arulagam and BNHS at the annual meeting, as well as the Indian Health Ministry for their role in achieving this despite the legal challenge by two pharmaceutical companies. Other veterinary drugs continue to become more available in South Asia, although some are known to be unsafe. So the first phases in Nov 2017 of safety-testing underway for Tolfenamic Acid (first of five drugs to be tested) by IVRI/BNHS team are hugely significant, with their completion and progress for the other drugs eagerly awaited. Progress of this work and all other South \& SE Asia updates is available in the annual SAVE report published in Jan 2018. VSZ work in Assam, UP and Madhya Pradesh has made important progress and prompt carcass testing results in MP have successfully led to targeted VSZ awareness efforts for dumps where diclofenac is still being detected. Gujarat called a statewide vulture review meeting in Oct 2017 with resolutions agreed following the worrying continued population declines reported by the GEER Foundation 2016 vulture survey. Five South Indian states met in Ooty, Jan 2018, and will be producing an action plan to improve inter-state coordination of surveys, and priority actions including replicating Tamil Nadu Government's pioneering step to stop Govt supply to vets of ketoprofen. In Pakistan an inter-Ministry meeting attended by WWF Pakistan in Nov 2017 is taking forward plans to ban or restrict ketoprofen, aceclofenac and nimesulide. In Bangladesh, which is leading the way on restricting toxic NSAIDs, these measures are already in place for both VSZs (that's $25 \%$ of the country), but it is hoped these measures will extend nationally soon as an important precedent for the region. 20 Himalayan Griffons (HG) have been rescued from various parts of Bangladesh, and taken care of at IUCN and Forest Dept facilities. A release of 12 of these is scheduled for $17 \mathrm{Mar}$ 2018 . Note that $16 \mathrm{HG}$ were similarly cared for in the previous 2016/17 winter and were mostly released. The annual SAVE meeting was hosted by the Ministry of Forests and IUCN in Bangladesh Sundarbans Nov 2017. It was attended by 40 delegates representing all five key countries, plus Bhutan for the first time. The full and summary reports are available which include the updated Blueprint Recovery Plan. It was coordinated with the Regional Steering Committee meeting in Dhaka two days later. In Cambodia the National Vulture Action Plan was released in August 2017 and the Cambodia Vulture Working Group formally became a SAVE partner. In China four Cinereous Vulture nests were found in the TienShan Mountains for the first time anywhere in China in 2016 and 17, although only one (25\%) was successful (MaMing et al. 2017).

\section{Middle East Round-up}

In NE Oman, 12 EVs (11 adults, 1 two yr old) were fitted with GPS tags in Jan. 2018. So far, they ranged through the Hajar Mountains and environs making regular visits to landfills, roosting in steep mountainous wadis, and perching on high voltage electricity pylons. Earlier tracking of 4 EVs since 2015 showed the importance of rubbish dumps, and that electrocution causes significant mortality. It shows that despite good food availability, the birds are very mobile. The data further suggest that ongoing upgrades to waste management in Oman, reducing the number of dumps from over 300 to 12 , may not have negative effects on vultures. Indeed, improved waste 
management may make food resources safer for vultures, simultaneously reducing human health risks. Some of the tagged birds are expected to be migrants, so new information on timing and migration routes should result, as well as determining breeding areas further north etc. Some tags also record altitude, and should clarify risks of collision with aircraft and wind turbines. This work is supported by the Bernd Meyburg Foundation for Raptor Research \& Conservation, the Greater Los Angeles Zoo Association, International Avian Research (IAR) and the Environment Society of Oman (ESO). To follow progress of the birds, IAR is posting updates on this link. In Israel, 8 captive born EVs were released at Mt. Carmel NR in Dec 2017. In total, 17 captive born EVs were released in 2017: four 2015 born, eight 2016 born, five 2017 born. This effectively reduced juvenile losses on migration which happened when releases were carried out at the natural fledging age. 8 of the 2017 released birds remained at the release site for the winter. Just one mortality so far was a 2015 bird bitten by a viper.

\section{European round-up}

The campaign to ban veterinary diclofenac continues in Europe, and hopes to prevent the drug being approved for veterinary use in Portugal - where there is a new application for veterinary use, and most significantly to try to prevent the renewal of such permission in Spain. Please sign the petition at www.banvetdiclofenac.com. Policy milestones included two brand new European species action plans for the Bearded and the Cinereous vultures, that have been submitted to the EU, while a new flyway action plan for the entire Cinereous Vulture distribution range was also produced by the CMS - this species has been increasing in western Europe, but its main global populations occur in central and eastern Asia.
Following the catastrophic poisoning event in Kresna Gorge, Bulgaria in Mar 2017, 14 Eurasian griffons have been fitted with GPS/GPRS tags. These birds are closely monitored for potential incidents with reaction teams on stand-by. The tracked birds movements can be followed as part of Vultures' back to LIFE. Bearded Vultures are now busily breeding across Europe both in nature and in captivity - a very successful conservation-breeding network is the basis for the ongoing reintroduction projects in the Alps, Andalusia, Grands Causses and Corsica. The first breeding programme egg appeared in late $\underline{\text { Nov, while the first chick hatched in Jan. Some }}$ mortality linked to West Nile virus is a cause for concern, but a new captive-breeding facility established in Armenia has increased capacity. There are now lots of eggs and chicks across Europe, and even a very old male (48 yrs) is still breeding. In the wild, it is hoped this breeding season will break last year's record in the Alps (49 pairs) - we know that at least two new pairs are breeding. A very successful citizen science simultaneous bearded vulture count was organised in Oct. across the Alps, while the annual Bearded Vulture meeting - one of the largest ever - approved the start of a new reintroduction project in the Maestrazgo-Els Ports mountains, between the Pyrenees and Andalusia, further progressing the Europe-wide species restoration project. An integral part of this programme is the project $\underline{\mathrm{LIFE}}$ GYPCONNECT, which is attempting to establish a population between the Pyrenees and the Alps, and which was recently featured in a great documentary in the TV channel ARTE. Some wild Bearded Vultures were also recovered injured and successfully re-released, like this one in Switzerland or this one in the Pyrenees - in the meantime, 'Adonis', after extensive travels, showed up back in France.

Five Egyptian Vultures tagged by the LIFE $\underline{\text { RUPIS project in Portugal-Spain wintered in }}$ their usual areas in Mali-Mauritania, but are 
now on their way back to Europe, but an Egyptian Vulture that had been tagged in Bulgaria was killed in Africa. The species is doing well in the Canary Islands due to an established conservation programme there, and a new project starting between the Canary Islands and Italy can hopefully boost the endangered Italian population (less than 10 pairs). More than half of these are in Sicily, where another conservation project is also working to prevent extinction. Further east, Egyptian Vultures from Eurasia winter in Oman, where a conservation and research project is providing new information.

Cinereous Vultures have been seen in good numbers migrating to Africa, including all the way to Mauritania. Back in Europe mostly good news, with increasing populations in PortugalSpain-France. In Mallorca too the unique island population continued to increase (36 pairs in 2017). Bulgarian partners are now very active with the preparations for the reintroduction of the first birds to their country (to happen later in 2017), including setting up nesting platforms. Further east a Cinereous Vulture which was rehabilitated back to the wild in Jordan was tagged and is wintering in Saudi Arabia. Eurasian Griffon Vultures have increased in Western Europe too, and this winter-early Spring, Spain and Portugal are organising an Iberia-wide breeding census in 2018. The species was counted across the $\underline{\text { Balkans }}$ this winter too, but the population in Cyprus is still extremely threatened. While in Portugal some rehabilitated griffons were released back into nature, others from rehabilitation centres in Spain were sent to $\underline{\text { Bulgaria, }}$, to help the successful reintroduction project in the central Balkan mountains, while a wild bird made it up all the way from Spain to Bulgaria on his own, with stops in France and Italy, providing evidence the populations in western and eastern Europe are connected. Many European griffons of course migrate to Africa, where some are killed or captured - like this example in Sudan, but when they travel back they often bring some African visitors, and so in Spain observations of Rüppell's Vultures are increasing too, and one has even been tagged - the first ever in Europe. In terms of threats, a number of poisoning incidents were reported in Europe, like one in Spain killing Griffon Vultures, or this one in Greece that killed two Cinereous Vultures, but there was also some progress - in Sardinia the antipoisoning dog units and conservations teams are advancing in the fight against poisoning, while in Portugal too some progress was registered. Electrocution continues to be a major threat, of course, like this example in Italy, and vultures in Europe die also because of collision with cables, but several projects are minimising both these threats, including using novel technology like drones to put anticollision bird markers in very difficult lines.

The role of national regulations affecting carcass disposal practices and the availability of food was highlighted in a recently published paper showed that vultures do not cross the border between Spain and Portugal despite the similar habitat. Disturbance to breeding Bearded Vultures in the Pyrenees by helicopters flying close to the nest has negatively affected productivity - $\underline{\text { but }}$ stakeholders are actively collaborating to mitigate this. Vultures often have a bad reputation even in Europe, and highlighting the ecosystem services they provide is important. A recent study of the perceptions of different stakeholders to vultures helps understand this. But interest in vultures is increasing - as this children's book shows, and recently there has been a local authority in France that has opened a brand new vulture trail opened in Vercors National Park.

Finally, the new EU funded project started addressing priority actions for the critically endangered Balkan population of Egyptian Vulture, along its flyway in 14 countries (from Europe through the Middle East to Africa). This 
is a flagship project of the Flyway Action Plan of EV (and a key component of the Vulture MsAP). In 2017, research on the Egyptian Vulture in the Balkans continued by monitoring of the breeding territories and productivity in Bulgaria, Greece, and Albania. A paper was published on the effects of closing a rubbish dump on breeding parameters of a Turkish EV population. In terms of telemetry, only five of 27 birds tagged since 2012 have survived by 2018. Major steps towards the in situ conservation of the species in the Balkans were the endorsement of the National Species Action

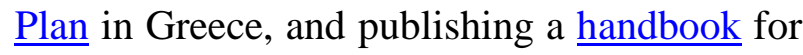
prevention of trafficking in protected species in Albania. Traditional supplementary feeding and nest guarding schemes in Bulgaria and Greece took place, and a new feeding site was established in Albania. In terms of ex situ conservation, the Green Balkans` Wildlife Rehabilitation and Breeding Centre prepares for the new breeding season of the Egyptian Vultures. Different campaigns were used to raise public awareness, such as "An extra mile for the Egyptian vulture", organising workshops and enforcing stakeholders' network to tackle the poisoning issue, and involving students in the fight against poisons in Greece. In Oct 2017, a workshop in Ankara, Turkey involved experts from Europe, Middle East and Africa.

A new European vulture mortality database has been established to collect all cases of vulture mortality - please contact David Izquierdo d.izquierdo@4vultures.org for more information.

\section{South America Round-up}

The shocking headline is 34 Andean Condors carbofuran-poisoned in one incident, Jan 2018 in Mendoza, central Argentina. Once Fundación Bioandina (FB) was alerted, it was reported to the Provincial Secretaria de
Ambiente y Ordenamiento Territorial. A multi sectoral team from the rural police, Fundación Cullunche, CONICET, Ecoparque Mendoza and FB investigated and determined the cause as Carbofuran poisoning. A dead puma and/or a dead cow were the likely source. FB has documented a major increase in such poisoning since 1991 and together with other researchers and NGOs initiated a campaign to solicit a law for the traceability of agricultural poisons in Argentina. It also calls for controlled use of agro-toxic substances, providing more support for ranchers, for educational programs, and to better enforce the existing law. The campaign can be found here. A further 19 condors had been similarly poisoned in Jan 2017, and there were several other poisoning events in 2017 totalling at least 66 condor deaths. Many Turkey and Black Vultures were also killed in the same way. In the district of Ciénaga, Magdalena, Colombia, two adult condors (from the population of only 40 in the Santa Marta mountains) were also found poisoned in Jan 2018.

Seasonal roadside counts in central Argentina were repeated after ten years by Hawk Mountain Sanctuary and CONICET scientists in Jul 2017 and Jan 2018. Results from this long-term monitoring effort are troubling. Although numbers of Caracaras and Andean Condors remained similar, those of Turkey and Black Vultures had declined precipitously, with Black Vultures showing the greatest declines.

Ecuador: Simultaneous counts of Andean Condor at 87 identified roost sites, by 283 trained volunteers in Sep 2017 by Andean Condor Research \& Conservation Project (PICE), led by The Peregrine Fund and Ilitío Wildlife Rescue Center, with Amaru Zoo of Cuenca City and Ministry of Envt. of Ecuador. 28 were counted of which 22 were adults. The low number of younger birds indicates a high juvenile mortality rate or low reproductive success in southern Ecuador. Only one was 
inside a National Protected Area (SNAP), although 39\% were in Área de Conservación y Uso Sustentable del Cóndor Andino, which is a new municipal reserve $(34,763 \mathrm{Ha})$ being created with the main objective to protect Condors (full report here). The protection of condors is being further strengthened in Southern Ecuador with the creation of the Río Negro-Sopladora NP in Morona-Santiago and Azuay in the eastern Andes (30,616 Ha). From Cusco, Peru, the thesis of Karol Mejia Espinoza suggests that the population of 14 condors are being outcompeted by domestic dogs for carrion food resources.

In Nov 2016, the National Working Group of the Andean Condor (GNTCA) in Ecuador conducted trial releases of three juvenile Andean Condors raised in captivity. Two males ( $1 \& 6$ yrs old) and a 4 yr female reared at Quito Zoo and Hacienda Zuleta. Fitted with solar satellite, VHF and wing tags they were released in paramo habitat of Hacienda Zuleta (at 3,800 $\mathrm{m})$. The six-year-old juvenile male signals disappeared after two weeks and probably died in the wild. The one-year-old male showed the most encouraging behaviour: he was observed flying frequently within a radius of four kilometers from the release site and interacting with a pair of wild condors. However, he did not feed on the carcasses supplied by the project, became weak and was recaptured; he died in captivity three weeks after his release. The four-year-old female dispersed up to six kilometers from the release site but did not feed on the supplied carrion. She, too, had to be recaptured and returned to captivity where she is currently part of the ex-situ breeding stock. The GNTCA evaluated the process concluding that despite the lack of success, the experimental trial was instructive but is in need of improvements before any future releases of condors should be attempted. Subsequently, the GNTCA carried out a strategic planning process on the ex-situ program and identified the need to maintain a captive population of condors with the main goal of reinforcing the wild and critically endangered condor population estimated at 100 individuals. In this context, the captive population of condors will mainly serve to fulfil the following two objectives: (1) Support environmental awareness and education initiatives at the national level and (2) reinforce the wild population by maintaining genetic diversity and reintroducing captive-bred condors.

\section{North America Round-up}

Satellite tracked Turkey Vultures tagged in SW Arizona by Hawk Mountain Sanctuary revealed that a minority of birds tagged in late spring are year round residents, but that most individuals are migratory, overwintering in Mexico, Guatemala, El Salvador, Panama, and Colombia, with individual birds returning to the same overwintering areas in subsequent winters. Meanwhile, birds tagged in winter in Arizona over-summer (and presumably breed) north and west of Arizona in California and the Pacific Northwest as far as Vancouver Island, Canada. Additional units will be deployed in S Arizona in 2018 winter and in coastal Washington State in late spring. Turkey Vultures using this this migratory system are being tested for lead to investigate contamination in birds with different movement behaviour.

Ongoing evidence is emerging in several US States of the threat of intoxication of wild, companion and captive animals through residues of sodium pentobarbital, originating from euthanized livestock carcasses, despite current guidelines that should prevent this from happening. Pet food companies in Jan 2018 recalled products. The overall extent of this threat to vultures is unclear, but turkey vultures have been exposed. 
Let us know if you receive this newsletter indirectly and wish to be added to the circulation list.

Chris Bowden

Andre Botha

Co-chairs: Vulture Specialist Group, IUCN Species Survival Commission

With thanks to the following contributors:

VSG Update Editor \& Asia: Chris Bowden

African Regional Co-chairs: Darcy Ogada, Masumi Gudka

European Regional Co-chair: José Tavares

Latin Americas Co-chair : Sergio Lambertucci

Additional contributions: Imad Cherkaoui, Ohad Hatzofe, Corinne Kendall, Mike McGrady, Bernd Meyburg, Stoyan Nicolov, Emilian Stoynov, Hernán Vargas, Rob Williams, Kerri Wolter. Editor Vulture News: Campbell Murn

VSG Admin Assistant: Lesley Jerome 